\title{
POLYMORPHISM IN THE AUSTRALIAN ACRIDIDÆ
}

\section{INHERITANCE OF COLOUR PATTERNS IN THE PLAGUE LOCUST, CHORTOICETES TERMINIFERA}

\author{
O. R. BYRNE \\ Botany Department, A.N.U., Canberra
}

Received 5.ii.67

\section{INTRODUCTION}

EXCEPT for extensive studies on the inheritance of colour patterns in two species of grouse locust, Paratettix texanus and Apotettix eurycephalus, by Nabours (1914, 1929) and Nabours and Stebbins (1950), there has been very little work on inheritance in the Orthoptera. These two species each possess a large number of bright coloured patterns and also a less conspicuous, wild-type colour pattern. In both species the conspicuous patterns are controlled by single genes, each completely dominant to the wild type. In $A$. eurycephalus there are 17 dominant colour pattern genes all of which are located within a map distance of about eight units on chromosome I. Twenty out of 23 dominant colour pattern genes in $P$. texanus have shown no recombination and therefore they may be allelic.

In the katydid, Ambylocorypha oblongifolia, there are pink and green forms, due to a single gene difference (Hancock, 1916; Nabours, 1928). The work of Sansome and La Cour (1935) suggested that there were at least 14 colour pattern loci in Chorthippus parallelus, two of which were linked. On the other hand, Creighton and Robertson (194I) found that in Chorthippus longicornis inheritance of colour patterns was determined by four allelic genes.

There has been no detailed study of the population genetics of colour pattern polymorphism in the Orthoptera. It is unfortunate that this aspect of genetics has not been pursued, particularly in those species where the mode of inheritance is known. Fisher's (1930, 1939) analysis of Nabour's extensive breeding data indicated that in Apotettix eurycephalus heterozygotes had a selective advantage of 7 per cent. over the dominant homozygotes and about 5 per cent. over the common recessive form. Also from data for natural populations of Paratettix texanus Fisher showed that the frequency of individuals heterozygous for two or more dominant genes was less than expected and he suggested that selective forces of the order of $4^{\circ}$ per cent. were operating against these forms in the field.

Rubtzov (1935) reported relative frequencies of four different colour patterns in Chorthippus albomarginatus from habitats which varied from dry to humid. His data suggested that in moist habitats, individuals which are phenotypically green (i.e. forma viridis) have a $2 \mathrm{~N}$ 
selective advantage over those which are brown (i.e. forma rubiginosa) whereas in dry habitats this situation is reversed.

Populations of the Australian plague locust, Chortoicetes terminifera, are invariably polymorphic for colour patterns. Key (I954) reported I 5 different colour patterns in species of Austroicetes and Chortoicetes of which seven occur in $C$. terminifera. Some of the patterns were similar to those described by Vorontzovsky (I928), Rubtzov (I935) and Uvarov (1943) for other species in the Acrididæ.

A study of colour pattern polymorphism in C. terminifera was started in I957. This paper deals with laboratory studies including the inheritance of the colour patterns.

\section{BIOLOGY OF CHORTOICETES TERMINIFERA}

Females deposit eggs in a pod below the soil surface. Swan (I956) reported that eggs do not develop at soil temperatures below $15^{\circ} \mathrm{C}$. and he suggested that under field conditions they usually remain dormant during the winter months and commence development after exposure to warm, moist conditions in late spring.

The species is distributed over most of the Australian continent. It is a strong, migratory insect and, as such, it has two different distributional regions; one in which it may occasionally be found and the other in which it is always found provided a diligent search is made for it in the right habitats at the right time of the year. Eggs are laid in compact soil close to vegetation and usually hatch in late spring. The adult stage is reached after about five moults and in seven to eight weeks from hatching. In the most favourable areas for locusts, three generations may be completed in the one season, i.e. from late spring to late autumn.

C. terminifera shows phase variation of the type described by Uvarov ( 1928 ) for Locusta migratoria. However, colour changes so characteristic of phase differences in Locusta and also the desert locust, Schistocerca gregaria, do not occur.

\section{INHERITANCE OF COLOUR PATTERNS}

\section{3(a) Culture methods}

Laboratory studies which involved matings between single pairs were set up in small cylindrical cages containing about four inches of sand or loam in which the females oviposited. Kikuyu grass, Pennisetum clandestinum, was used as food throughout and this was supplemented by a dry mixture of bran, casein and yeast (4:4:I) during the nymphal stages. The locusts were reared at $32 \pm 2^{\circ} \mathrm{C}$. Egg pods were removed from the soil and incubated at $35^{\circ} \mathrm{C}$. on moist Wettex in Petri dishes. Males and females were separated during the fourth or fifth instar and new matings were set up after the final moult.

Under the rearing conditions described above, locusts completed 
their nymphal development in 25 to 28 days after hatching. The generation time under the most favourable conditions was 7 weeks compared with i I weeks under field conditions.

The study of inheritance of colour patterns was started during March 1957. The original parents were obtained from Waikerie, South Australia, and Perth, West Australia. Further collections from several localities in New South Wales, South Australia and West Australia were introduced into the breeding programme during subsequent years.

\section{3(b) Description of colour patterns}

The inheritance studies were concerned with four colour patterns which corresponded to Keys (I954) description of albomedia, nigrovirgata, rubiginosa and trilineata. During the investigations it was found that, of the six hybrid combinations between these colour patterns, five were phenotypically different from either parent, i.e. nine phenotypically different colour patterns could easily be recognised. These patterns differ not only in colour but also in the distribution of the different colours over the lateral and dorsal surfaces of the insect. The most striking feature of each colour pattern, therefore, is the particular contrast between light and dark coloured areas as illustrated in plate I. The light coloured areas may be white, cream-coloured, yellow or orange and the dark areas may be brown, grey or black, depending on the genotype of the individual. The colour patterns may be either slightly modified or in extreme cases completely masked by a green pigment. The production of this green pigment appears to be controlled by environment and the relative frequency of individuals showing it varies from population to population. Also, the proportion of green individuals among the different genotypes is variable, being the highest for $F^{n} F^{n}$ and lowest for $F^{r} F^{r}$.

\section{3(c) Genetical analysis}

(i) Inheritance data. Data on colour pattern inheritance were obtained from 9I successful matings which included 35 different combinations of colour patterns or types of mating. Frequencies of different colour patterns observed among the offspring are summarised in table I. Data from different crosses involving the same type of mating were homogeneous and have been pooled. Also no differences between reciprocal crosses or with respect to sex were observed.

In table 2 are given chi-square values testing for heterogeneity of colour pattern frequencies between the early nymphal stages and adults from 28 separate families. There was no heterogeneity indicating no differential mortality with respect to colour patterns occurred when the locusts were reared in the laboratory. Consequently family data involving either nymphs or adults may be used in testing agreement with our hypothesis for inheritance of colour patterns. 
(ii) Genetical basis. True breeding stocks for four colour patterns were obtained. In offspring where segregation for colour pattern occurred, the ratios were approximately I:I, I:2:I or I:I:I:I. It is therefore suggested that colour patterns in $C$. terminifera are inherited

TABLE I

Colour pattern data for offspring from 35 different mating types

\begin{tabular}{|c|c|c|c|c|c|c|c|c|c|c|c|}
\hline \multirow{2}{*}{ Mating type } & \multirow{2}{*}{$\begin{array}{l}\text { No. of } \\
\text { matings }\end{array}$} & \multirow{2}{*}{$\begin{array}{c}\text { Total } \\
\text { No. of } \\
\text { offspring }\end{array}$} & \multicolumn{9}{|c|}{ Genotype of offspring } \\
\hline & & & $\begin{array}{l}F^{a} F^{a} \\
F^{a} F^{r}\end{array}$ & $F^{a} F^{n}$ & $F^{a} F^{t}$ & $F^{n} F^{n}$ & $F^{n} F^{r}$ & $F^{n} F^{t}$ & $F^{r} F^{r}$ & $F^{r} F^{t}$ & $F^{t} F^{t}$ \\
\hline I. $F^{t} F^{t} \times F^{t} F^{t}$ & 5 & I 60 & $\cdots$ & $\cdots$ & $\cdots$ & $\cdots$ & $\cdots$ & $\cdots$ & $\ldots$ & $\ldots$ & I 60 \\
\hline 2. $F^{t} F^{t} \times F^{r} F^{r}$ & 3 & $5^{8}$ & $\cdots$ & $\cdots$ & $\cdots$ & $\cdots$ & $\cdots$ & $\cdots$ & $\cdots$ & $5^{8}$ & ... \\
\hline 3. $F^{t} F^{t} \times F^{n} F^{t}$ & I & 27 & $\cdots$ & $\cdots$ & $\cdots$ & $\cdots$ & $\cdots$ & I 3 & $\cdots$ & $\ldots$ & I 4 \\
\hline 4. $F^{t} F^{t} \times F^{n} F^{r}$ & 4 & I 35 & $\cdots$ & $\cdots$ & $\cdots$ & $\cdots$ & $\cdots$ & $7 \mathrm{I}$ & $\cdots$ & 64 & $\cdots$ \\
\hline 5. $F^{n} F^{n} \times F^{n} F^{n}$ & 3 & 32 & $\cdots$ & $\cdots$ & $\cdots$ & $3^{2}$ & $\cdots$ & $\cdots$ & $\cdots$ & $\ldots$ & $\cdots$ \\
\hline 6. $F^{n} F^{n} \times F^{r} F^{r}$ & 2 & 58 & $\cdots$ & $\cdots$ & $\cdots$ & $\cdots$ & $5^{8}$ & $\ddot{0}$ & $\cdots$ & $\cdots$ & $\cdots$ \\
\hline 7. $F^{n} F^{n} \times F^{n} F^{t}$ & 3 & 297 & $\cdots$ & $\cdots$ & $\cdots$ & I 59 & $\cdots$ & 138 & $\cdots$ & $\cdots$ & $\cdots$ \\
\hline 8. $F^{n} F^{n} \times F^{r} F^{t}$ & I & 6 I & $\cdots$ & $\cdots$ & $\cdots$ & $\cdots$ & 28 & 33 & $\cdots$ & $\cdots$ & $\cdots$ \\
\hline 9. $F^{n} F^{n} \times F^{a} F^{t}$ & 2 & 23 & $\cdots$ & I I & $\cdots$ & $\cdots$ & $\cdots$ & I 2 & $\cdots$ & $\cdots$ & $\cdots$ \\
\hline 10. $F^{n} F^{n} \times F^{a} F^{n}$ & I & IO & $\cdots$ & 7 & $\cdots$ & 3 & $\cdots$ & $\cdots$ & $\ddot{0}$ & $\cdots$ & $\cdots$ \\
\hline I I. $F^{r} F^{r} \times F^{r} F^{r}$ & 7 & 284 & $\cdots$ & $\cdots$ & $\cdots$ & $\cdots$ & $\cdots$ & $\cdots$ & 284 & $\cdots$ & $\cdots$ \\
\hline I 2. $F^{r} F^{r} \times F^{n} F^{t}$ & I & I 7 & $\cdots$ & $\cdots$ & $\cdots$ & $\cdots$ & I I & $\cdots$ & $\cdots$ & 6 & $\cdots$ \\
\hline I3. $F^{r} F^{r} \times F^{r} F^{t}$ & I3 & 467 & $\cdots$ & $\cdots$ & $\cdots$ & $\cdots$ & $\cdots$ & $\cdots$ & 236 & $23 I$ & $\cdots$ \\
\hline I4. $F^{r} F^{r} \times F^{a} F^{t}$ & I & 34 & 20 & $\cdots$ & $\cdots$ & $\cdots$ & $\cdots$ & $\cdots$ & $\cdots$ & I 4 & $\cdots$ \\
\hline I 5. $F^{r} F^{r} \times F^{n} F^{r}$ & 5 & I 68 & $\cdots$ & $\cdots$ & $\cdots$ & $\cdots$ & 96 & $\cdots$ & 72 & $\cdots$ & $\cdots$ \\
\hline I6. $F^{a} F^{a} \times F^{a} F^{a}$ & I & 8 & 8 & $\cdots$ & $\cdots$ & $\cdots$ & $\cdots$ & $\cdots$ & $\cdots$ & $\cdots$ & $\cdots$ \\
\hline I 7. $F^{a} F^{r} \times F^{a} F^{r}$ & 2 & 77 & 55 & $\cdots$ & $\cdots$ & $\cdots$ & $\cdots$ & $\cdots$ & 22 & $\cdots$ & $\cdots$ \\
\hline I8. $F^{n} F^{t} \times F^{n} F^{t}$ & 2 & 45 & $\cdots$ & $\cdots$ & $\cdots$ & I 4 & $\cdots$ & I9 & $\cdots$ & $\cdots$ & 12 \\
\hline I9. $F^{n} F^{t} \times F^{r} F^{t}$ & 2 & 38 & $\cdots$ & $\cdots$ & $\cdots$ & $\cdots$ & I 7 & 7 & $\cdots$ & IO & 4 \\
\hline 20. $F^{n} F^{t} \times F^{a} F^{t}$ & 2 & $5^{8}$ & $\cdots$ & I 3 & 9 & $\cdots$ & $\cdots$ & 22 & $\cdots$ & $\cdots$ & I 4 \\
\hline 21. $F^{n} F^{t} \times F^{n} F^{r}$ & I & 4 & $\cdots$ & $\cdots$ & $\cdots$ & I & $\cdots$ & $\cdots$ & $\cdots$ & 3 & $\cdots$ \\
\hline 22. $F^{n} F^{t} \times F^{a} F^{r}$ & I & 24 & $\cdots$ & 9 & 9 & $\cdots$ & 3 & $\cdots$ & $\cdots$ & 3 & $\cdots$ \\
\hline 23. $F^{r} F^{t} \times F^{r} F^{t}$ & 3 & 42 & $\cdots$ & $\cdots$ & $\cdots$ & $\cdots$ & $\cdots$ & $\cdots$ & 10 & I9 & I 3 \\
\hline 24. $F^{r} F^{t} \times F^{n} F^{r}$ & 4 & I 42 & $\cdots$ & $\cdots$ & $\cdots$ & $\cdots$ & 3 I & $4^{8}$ & 29 & 34 & $\cdots$ \\
\hline 25. $\quad F^{r} F^{t} \times F^{a} F^{n}$ & I & 46 & 8 & $\cdots$ & 12 & $\cdots$ & I 5 & II & $\cdots$ & $\cdots$ & $\cdots$ \\
\hline 26. $F^{r} F^{t} \times F^{a} F^{r}$ & 2 & 8 & $\cdots$ & $\cdots$ & $\cdots$ & $\cdots$ & $\cdots$ & $\cdots$ & 2 & 6 & $\cdots$ \\
\hline 27. $F^{a} F^{t} \times F^{a} F^{t}$ & 3 & 74 & I 6 & $\cdots$ & 35 & $\cdots$ & $\cdots$ & $\cdots$ & $\cdots$ & $\cdots$ & 23 \\
\hline 28. $F^{a} F^{t} \times F^{n} F^{r}$ & I & 8 & 2 & 2 & $\cdots$ & $\cdots$ & $\cdots$ & I & $\cdots$ & 3 & $\cdots$ \\
\hline 29. $F^{a} F^{t} \times F^{a} F^{n}$ & 2 & 17 & 2 & 6 & I & $\cdots$ & $\cdots$ & 8 & $\cdots$ & ... & $\cdots$ \\
\hline 3o. $F^{a} F^{t} \times F^{a} F^{r}$ & I & I 6 & I & $\cdots$ & I 3 & $\cdots$ & $\cdots$ & $\cdots$ & $\cdots$ & 2 & $\ldots$ \\
\hline 3I. $F^{n} F^{r} \times F^{n} F^{r}$ & 3 & 36 & $\ldots$ & $\cdots$ & $\cdots$ & 8 & I 9 & $\cdots$ & 9 & $\cdots$ & $\cdots$ \\
\hline 32. $F^{n} F^{r} \times F^{a} F^{n}$ & 2 & I 5 & 3 & I & $\cdots$ & 5 & 6 & $\cdots$ & $\cdots$ & $\cdots$ & $\cdots$ \\
\hline 33. $F^{n} F^{r} \times F^{a} F^{r}$ & 2 & 24 & 8 & I & $\cdots$ & $\cdots$ & I 2 & $\cdots$ & 3 & $\cdots$ & $\cdots$ \\
\hline 34. $F^{a} F^{n} \times F^{a} F^{n}$ & 3 & 23 & 5 & I I & $\cdots$ & 7 & $\cdots$ & $\cdots$ & $\cdots$ & $\cdots$ & $\cdots$ \\
\hline 35. $F^{a} F^{n} \times F^{a} F^{r}$ & I & I I & 5 & $\cdots$ & $\cdots$ & $\cdots$ & 6 & $\cdots$ & $\cdots$ & $\cdots$ & $\cdots$ \\
\hline TOTAL & 9 I & 2547 & $\cdots$ & $\cdots$ & $\cdots$ & $\cdots$ & $\cdots$ & $\cdots$ & $\cdots$ & $\cdots$ & $\cdots$ \\
\hline
\end{tabular}

by four allelic genes $F^{a}, F^{n}, F^{r}$, and $F^{t}$-a tetrallelic locus would give ten genotypes of which four are homozygous and six are heterozygous.

The phenotypes corresponding to the ten genotypes are illustrated in plate I. The genotypes $F^{a} F^{a}$ and $F^{a} F^{r}$ appear to have the same phenotype although among sibs the dark areas are paler in $F^{a} F^{r}$ than in $F^{a} F^{a}$. The intensity of pigmentation is easily modified by environment, and is an unreliable criterion for recognising different colour patterns - these are distinguished solely by pattern differences. 
(iii) Analysis of data. Chi-square values testing the agreement between observed and expected frequencies on the basis of the hypothesis are given in table 3 . In a sample of 23 , one or two of the $\chi^{2}$

TABLE 2

Chi-square values for heterogeneity of colour pattern frequencies between early nymphal stages and adults of 28 different families

\begin{tabular}{|c|c|c|c|c|c|}
\hline No. of mating & D.F. & Chi-square & No. of mating & D.F. & Chi-square \\
\hline 3 & I & $0.9^{8}$ & $53^{2}$ & I & I. 06 \\
\hline IO & I & 0.04 & $54^{I}$ & I & 0.08 \\
\hline I 4 & I & 0.00 & 545 & I & 0.05 \\
\hline I 20 & I & 0.25 & 547 & 2 & $5 \cdot 46$ \\
\hline I 23 & I & $\mathrm{I} \cdot 28$ & $55^{\circ}$ & 3 & $3 \cdot 40$ \\
\hline I $4 \mathrm{I}$ & I & 0.00 & $55^{I}$ & I & O.I 3 \\
\hline I 52 & I & $0.4^{\circ}$ & $55^{2}$ & 2 & O.I9 \\
\hline I 57 & I & 0.01 & 553 & 2 & $I \cdot 30$ \\
\hline 207 & 3 & $0 \cdot 4^{6}$ & 554 & 2 & 0.28 \\
\hline 209 & I & 0.09 & $56 \mathrm{I}$ & I & $0 \cdot 3^{6}$ \\
\hline 304 & I & $0 \cdot 73$ & $5^{6} 5$ & I & 0.00 \\
\hline 405 & I & 0.05 & $5^{84}$ & I & 0.05 \\
\hline 505 & 2 & 0.04 & 612 & I & 0.05 \\
\hline $53^{\mathrm{I}}$ & I & $2 \cdot 25$ & $622 \mathrm{~A}$ & I & $0 \cdot 72$ \\
\hline
\end{tabular}

values are expected to be significant at the 5 per cent. level and should not therefore be taken seriously. The data on the whole agree reasonably well with the multiple allelic hypothesis.

TABLE 3

Chi-square values testing the agreement between observed and expected frequencies for 23 out of the 35 types of mating

\begin{tabular}{|c|c|c|c|c|c|}
\hline $\begin{array}{l}\text { Mating } \\
\text { type No. }\end{array}$ & D.F. & Chi-square & $\begin{array}{l}\text { Mating } \\
\text { type No. }\end{array}$ & D.F. & Chi-square \\
\hline $\begin{array}{r}3 \\
4 \\
7 \\
8 \\
9 \\
\text { I0 } \\
\text { I } 2 \\
\text { I } 3 \\
\text { I } 4 \\
\text { I } 5 \\
\text { I } 7 \\
\text { I } 8\end{array}$ & $\begin{array}{l}\text { I } \\
\text { I } \\
\text { I } \\
\text { I } \\
\text { I } \\
\text { I } \\
\text { I } \\
\text { I } \\
\text { I } \\
\text { I } \\
\text { I } \\
2\end{array}$ & $\begin{array}{l}0.04 \\
0.36 \\
\mathrm{I} \cdot 34 \\
0.20 \\
0.04 \\
\mathrm{I} \cdot 60 \\
\mathrm{I} \cdot 47 \\
0.05 \\
\mathrm{I} \cdot 06 \\
3.43 \\
0.52 \\
\mathrm{I} \cdot \mathrm{I} 5\end{array}$ & $\begin{array}{l}19 \\
20 \\
22 \\
23 \\
24 \\
25 \\
27 \\
31 \\
33 \\
34 \\
35 \\
\ldots\end{array}$ & $\begin{array}{c}3 \\
3 \\
3 \\
2 \\
3 \\
3 \\
2 \\
2 \\
3 \\
2 \\
1 \\
\ldots\end{array}$ & $\begin{array}{c}8 \cdot 74 \\
6 \cdot 14 \\
6 \cdot 00 \\
0 \cdot 81 \\
6 \cdot 25 \\
2 \cdot 17 \\
1 \cdot 54 \\
0 \cdot 17 \\
12 \cdot 33 \\
2 \cdot 25 \\
0.09 \\
\ldots\end{array}$ \\
\hline
\end{tabular}

(iv) Dominance. The phenotypes $F^{a} F^{a}, F^{n} F^{n}$ and $F^{t} F^{t}$ have in common a well-developed contrast between pale and dark coloured areas. In the other homozygote $F^{r} F^{r}$ the contrast is greatly reduced so that the whole body surface is relatively uniform except for a mottled appearance. Genotypes heterozygous for the $F^{r}$ allele also 
have conspicuous phenotypes. In other words, contrasting patterns are dominant over the relatively uniform rubiginosa pattern. The alleles $F^{a}, F^{n}$ and $F^{t}$ are regarded as being dominant genes. However, the only case of complete dominance was for $F^{a}$ over $F^{r}$. Among genotypes heterozygous with respect to the dominant allele, $F^{a}$ is more completely dominant than $F^{n}$ and $F^{t}$. The order of dominance for the four alleles can be represented by $F^{a}>F^{n}=F^{t}<F^{r}$.

(v) Multiple allelism versus close linkage. Two or more non-allelic genes may behave in transmission as multiple alleles provided no recombination between them can be detected. For closely linked loci (up to I per cent. recombination, say) a large number of offspring would probably have to be scored before detecting a recombinant. Therefore our hypothesis of multiple allelism does not exclude the possibility of close linkage. However, from the data, the upper limit of the recombination percentage may be estimated. The limit is a function of the number of offspring and will decrease as larger numbers are examined, provided no recombinants are detected.

A minimum of three loci is necessary to explain the inheritance of colour patterns by closely linked loci. The recessive rubiginosa may be represented genotypically as $\frac{a n t}{a n t}$. Most heterozygotes would be in repulsion phase, e.g. $F^{n} F^{t}$ would be $\frac{a \mathcal{N} t}{a n T}$. Where " $p$ " is the recombination percentage between $\mathcal{N}$ and $T$, the expectation of offspring in terms of " $p$ " from a repulsion phase back-cross would be:

Non-recombinants

$$
\frac{a \mathcal{N} t}{a n \mathcal{T}} \times \frac{a n t}{a n t} \rightarrow \frac{a \mathcal{N} t}{a n t}, \frac{a n T}{a n t}
$$

$\begin{array}{lll}\text { Relative } & \mathrm{I}-p \\ \text { Frequency } & \frac{\mathrm{I}-p}{2}\end{array}$

\section{Recombinants}

$$
\begin{aligned}
& \frac{a \mathcal{N} T}{a n t}, \frac{a n t}{a n t} \\
& \frac{p}{2} \quad \frac{p}{2}
\end{aligned}
$$

If no recombinants are observed in " $n$ " offspring, then the upper 95 per cent. confidence limit for the recombination percentage is calculated by equating the first term of the expansion of $(q+p)^{n}$ to $0 \cdot 05$, i.e. $(\mathrm{I}-p)^{n}=0 \cdot 05$. Upper limits for the three regions have been estimated and are given in table 4 .

TABLE 4

Upper limit of recombination with 0.95 certainty for the regions $A-\mathcal{N}, A-\mathcal{T}$ and $\mathcal{N}-\mathcal{T}$

\begin{tabular}{|c|c|c|c|c|}
\hline Region & Mating type No. & $\begin{array}{c}\text { Expected proportion } \\
\text { recombination }\end{array}$ & $n$ & $p(\%)$ \\
\cline { 2 - 4 } A-N & 25 & $p$ & 46 & 6.3 \\
A-T & $9,14,28$ & $p$ & 65 & $4 \cdot 5$ \\
N-T & 7,18 & $p / 2$ & $34^{2}$ & 1.7 \\
\hline
\end{tabular}




\section{DISCUSSION}

The colour pattern polymorphism in C. terminifera is probably controlled by four allelic genes. A polymorphism involving similar colour patterns is found in other grasshopper species which are taxonomically related to Chortoicetes (Key, r954). It is therefore likely that the polymorphism is an old one and it may have existed in the ancestors of present-day species.

Animals such as grouse locusts (Nabours and Stebbins, r950), land snails (Cain and Sheppard, r950), fish (Gordon and Gordon, I950) and beetles (Tan, r949) all have in common a number of conspicuous colour patterns which are completely dominant to a prevalent, less conspicuous pattern. This latter pattern has been called a "universal recessive". In many of these examples the mutant genes are at different but closely linked loci. However, in C. terminifera the polymorphism seems to be controlled by allelic genes and no one pattern may be regarded as being prevalent. The rubiginosa $\left(F^{r} F^{r}\right)$ pattern, although not universally recessive, is similar to the " universal recessive" pattern in the other polymorphisms by being the least conspicuous of the colour patterns. Albomedia $\left(F^{a} F^{a}\right)$ is completely dominant to rubiginosa, whereas both nigrovirgata $\left(F^{n} F^{n}\right)$ and trilineata $\left(F^{t} F^{t}\right)$ are incompletely dominant to it. If, during the evolution of dominance, there was a relaxation of selection favouring modification of heterozygotes, then complete dominance may not result. This change in selection could result either from a marked decrease in the number of predators or if the heterozygotes possessed some physiological advantage over the dominant homozygotes. If the polymorphism were maintained entirely by the selective action of predators, and if predators became rare, then the mutant genes would decrease in frequency unless they increased viability in some other way.

\section{SUMMARY}

I. The Australian plague locust is polymorphic for at least nine colour patterns which appear to be determined by a single locus with four alleles, $F^{a}, F^{n}, F^{r}$ and $F^{t}$. The colour patterns of heterozygotes can be recognised but $F^{a} F^{r}$ is indistinguishable from $F^{a} F^{a}$.

2. A satisfactory technique for rearing colonies of this insect in the laboratory has been developed. There is no diapause and a generation is completed in seven weeks at $32^{\circ} \mathrm{C}$.

3. Differences in colour pattern may be observed in the first nymphal instar and they become more distinctive as the insect increases in size.

Acknowledgments.- The author is grateful to Professor J. H. Bennett for his interest and guidance during the course of this investigation. The study was carried out within the Genetics Department, University of Adelaide, during the tenure of a Services Canteens Trust Fund Scholarship and a C.S.I.R.O. Senior Studentship. 


\section{REFERENCES}

GAIN, A. J., AND SHEPPARD, P. M. I95o. Selection in the polymorphic land snail Cepcea nemoralis. Heredity, 4, 275-294.

CREIGHTON, M., AND ROBERTSON, W. R. B. I94I. Genetic studies on Chorthippus longicornis. $\mathcal{F}$. Hered., 32, 339-34 I.

FISHER, R. A. I930. The evolution of dominance in certain polymorphic species. Amer. Nat., 64, 385-4.06.

Fisher, R. A. 1939. Selective forces in wild populations of Paratettix texanus. Ann. Eugen., 9, IO9-123.

GORDON, H., AND GORDON, M. I950. Colour patterns and gene frequencies in natural populations of platyfish. Heredity, 4, 6 $1-73$.

HANCOCK, J. L. I9I6. Pink katydids and the inheritance of pink colouration. Ent. Newes, 27, 70-82.

KEY, к. H. L. 1954. The taxonomy, phases, and distribution of the genera Chortoicetes Brunn and Austroicetes Uv. (Orthoptera:Acridide), 237 pp. (C.S.I.R.O., Canberra).

NABours, R. K. I9I4. Studies of inheritance in Orthoptera I. Paratettix texanus. 7. Genetics, 3, I4I-I 70 .

NABOURS, R. K. I928. Hancock's studies of inheritance in green and pink Katydids, Ambylocorypha oblongifolia De Greer. Ent. Newes, 40, I4-16.

Nabours, R. K. r929. The genetics of the Tettigidae (grouse-locusts), Bibl. Genet., 5, 27-IO4.

Nabours, R. K., And stebbins, F. M. I950. Cytogenetics of the grouse locust, Apotettix eurycephalus Hancock. Tech. Bull. Kansas Agric. Exp. Stn., 67, I-1 I 7.

RubTzov, I. A. 1935. Phase variation in non-swarming grasshoppers. Bull. Ent. Res., 26, 499-524.

Sansome, F. W., AND LA cour, L. 1935. The genetics of grasshoppers Chorthippus parellelus. J. Genet., 30, 415-422.

swan, D. G. 1956. Locusts and grasshoppers in South Australia. Dept. Agric. S. Aust. Bull., 440.

TAN, c. c. I949. Seasonal variations in colour patterns in Harmonia axynidis. Proc. 8th Int. Cong. Genet. Hereditas Supp. Vol., 669-67o.

uvarov, B. P. 1928. Locusts and Grasshoppers, 352 pp. (Commonw. Inst. Ent., London).

UVArov, B. P. I 943 . The tribe Thrinchini of the sub-family Pamphaginae, and the interrelations of the subfamilies (Orthoptera). Trans. R. Ent. Soc. London, 93, I -72 .

VORONTZOVSKY, P. A. I928. On the question of homologous ranges of colour variation in Acrididæ (In Russian.) Bull. Orenburg Pl. Prot. Sta., 1, 27-39. 
Plate I
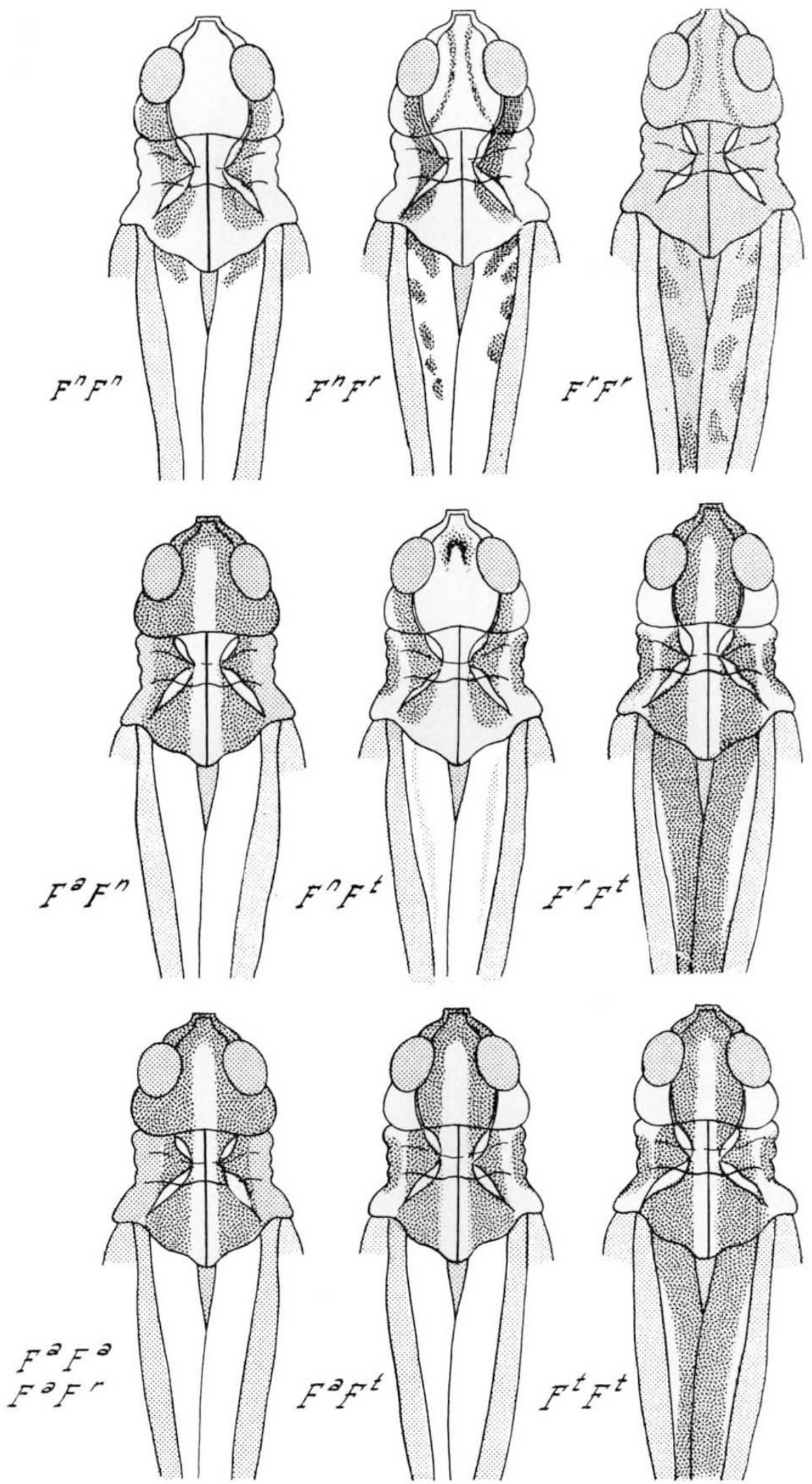

Dorsal views of the diagnostic features of the different colour patterns in Chortoicetes terminifera. 